\title{
Properties and Structure of Microcrystalline Chitosan and Hydroxyapatite Composites
}

\author{
Luciano Pighinelli1*, Magdalena Kucharska \\ ${ }^{1}$ Lutheran University of Brazil (ULBRA), Canoas, Brazil \\ ${ }^{2}$ Institute of Biopolymers and Chemical Fibers-IBWCh, Lodz, Poland \\ Email: pppgemps@ulbra.br, Ipighinelli@hotmail.com, biomater@ibwch.lodz.pl
}

Received 11 February 2014; revised 26 March 2014; accepted 21 April 2014

Copyright @ 2014 by authors and Scientific Research Publishing Inc.

This work is licensed under the Creative Commons Attribution International License (CC BY). http://creativecommons.org/licenses/by/4.0/

(c) (i) Open Access

\section{Abstract}

The skeletal system in the human body is very important, provides support and gives shape to the body and provides a network between all soft tissues. The most common problems in hard tissues are bone fractures, defects or diseases which needed to be treated. The developments in artificial bone area seem to solve most of the hard tissue problems, on the other hand artificial bones themselves may cause other problems and in many cases they do not have sufficient mechanical properties and/or good biocompatibility. The importance of chitosan and its derivatives like microcrystalline chitosan has grown significantly over the last two decades due to its renewable and biodegradable source, and also because of the increase in the knowledge of its functionality in the technological and biomedical applications. The excellent biocompability, biofunctionality, and non-antigenic property make the chitosan and its derivatives as a microcrystalline chitosan an ideal material for tissue regeneration. To improve the suitability of chitosan for bone tissue engineering, the composites of MCCh and hydroxyapatite were studied. In the present work the characterization of the MCCh and composites with HAp in form of films and sponges, is based on physico-chemical tests, morphology, structure, particle size of HAp powder and distribution in the polymer matrix. The compositions with film and sponge shape are derived from the junction of two different materials, containing organic and inorganic substances. All sponge preparations, with HAp/MCCh have a well-shaped 3-dimensional structure, which could be used as implants in orthopedic surgery for a scaffolds base for medical applications.

\section{Keywords}

Chitosan; Microcrystalline Chitosan; Hydroxyapatite; Functional Biopolymer;

Tissue Engineering

\footnotetext{
${ }^{*}$ Corresponding author.
}

How to cite this paper: Pighinelli, L. and Kucharska, M. (2014) Properties and Structure of Microcrystalline Chitosan and Hydroxyapatite Composites. Journal of Biomaterials and Nanobiotechnology, 5, 128-138. 


\section{Introduction}

Every year, millions of people are suffering from bone disease arising from trauma, tumor, bone fractures or defects making a massive pressure in all heart systems in all countries and unfortunately some patients are dying due to insufficient of ideal bone substitute or treatment.

Much attention has been given to use chitosan in biomedical applications, for example, formation in tissue regenerative therapy. The superior tissue compatibility, biofunctionality and non-antigenic property make chitosan an ideal material for tissue regeneration [1].

Polyaminosaccharides, especially chitosan (poly(B-(1,4)-2-amino-2-amino-2-deoxy-D-glucopiranose)) and its derivatives, are characterized by excellent biostimulation properties which facilitate reconstruction and vascularrization of damaged tissues, also compensate the shortcomings of cells components, which are conductive for small scar forming [2] [3]. This cationic property is the basis of many potential applications of chitosan that can be considered as a linear polyelectrolyte with a high charge density which can interact with negative charged surfaces, like proteins and anionic polysaccharides [4].

Currently, chitosan and its derivatives have been used also in water treatment, production of cosmetics, drugs and medicine, food additives, semi-permeable membranes and the development of biomaterials [5]. One of the most important parameters to determine the chitosan is the degree of acetylation and the molecular weight, and this characteristic is directly related to the hydrogen bonding existing in this biopolymer, affecting its structure, solubility, reactivity and the viscosity [6].

Chitosan and its derivatives as a MCCh are often used for the preparation of the biodregradeble biomaterials. Chitosan of acetylation degree over $80 \%$ and average molecular weight around $350 \mathrm{kDa}$ demonstrated the highest level of activity [7]. Chitosan could be used as a base material for scaffold devices and as modification tools for currently used biomedical devices in improving tissue regeneration efficacy. Also, it can expand the feasibility of combinative strategy of controlled drug release idea and tissue engineered tissue formation in reconstructive therapy in the field of periodontics, orthopedics, cancer and plastic surgery [8].

Several new forms of dressings are elaborated in form of hydrogels, films or sponges. MCCh is a modified chitosan form elaborated by the aminoglucose macromolecule aggregation method.

MCCh is characterized by special properties of initial chitosan such as biocompatibility, bioactivity, non-toxic, hydrophility with the same extraordinary behavior like direct film-forming and creation of molecular and supermolecular structure during its manufacture. The MCCh is very suitable in medical application, especially for wound dressings [9] [10]. However, application of microcrystalline chitosan form shows resistance to the dissolution in neutral $\mathrm{pH}$ as well as prolongation of the biodegradation due to the relatively high crystallinity of the formed biocomposites [11]. Hydroxyapatite (HAp), $\left(\mathrm{Ca}_{10}\left(\mathrm{Po}_{4}\right)_{3} \mathrm{OH}\right)$ is the major inorganic compound in mammalian hard tissue and is highly recognized and used for its biocompatibility. It has been incorporated into a wide variety of biomedical devices including dental implants, dental application, biodegradable scaffolds, and other types of orthopedic implants [12] [13].

The calcium phosphates are fully supported by the physiological environment and the osseo-conductive have been proven to be excellent in bone replacement, enabling rates of resorption/replacement very favorable. The HAp is more similar to natural bone than other calcium phosphate-like $\beta$-TCP, $\left(\mathrm{Ca}_{3}\left(\mathrm{Po}_{4}\right)_{2}\right)$. However, the resorption of HAp is extremely low compared with that of $\beta$-TCP [14].

The performance of a polymer medical device as a scaffold depends not only on its bulk material properties, but also on the surface characteristics of the material [15].

The aims of the work were the preparation of selected forms of the initial chitosan like microcrystalline chitosan (MCCh), physico-chemical characterization, elaboration of the method for preparation composites with MCCh/HAp (films and sponges). To improve the suitability of chitosan and its derivatives as a MCCh for bone tissue engineering, the composites of MCCh and hydroxyapatite could be applied.

\section{Materials and Methods}

\subsection{Materials}

Initial chitosan from Primex Co trade name Chito Clear FG90 was used, characterized by: average molecular weight $\left(\mathrm{M}_{\mathrm{v}}\right)=342 \mathrm{kD}$, deacetylation degree $(\mathrm{DD})=82 \%$, ash content $=1.7 \%$, moisture content $12.77 \%$ Microcrystalline chitosan $(\mathrm{MCCh})$ characterized by: average molecular weight $\left(\mathrm{M}_{\mathrm{v}}\right)=330 \mathrm{kD}$, deacetylation degree $(\mathrm{DD})=82 \%$, ash content $=0.7 \%$, water retention value $(\mathrm{WRV})=598 \%$, dry polymer content $($ dry polymer $)=$ 
2.0 and 2.95\%. Hydroxyapatite $\left(\mathrm{Ca}_{10}\left(\mathrm{Po}_{4}\right)_{6} \mathrm{OH}\right)$-Sigma Aldrich Lab., Germany. Plasticizer-Glycerol $\left(\mathrm{C}_{3} \mathrm{H}_{8} \mathrm{O}_{3}\right)$ 99\%, pure p.a., Sigma-Aldrich, Germany. Hydrochloric ac. 34.9\% p.a., manufactured by Chempur, Poland.

\subsection{Methods}

\subsubsection{Preparation of Microcrystalline Chitosan}

Microcrystalline chitosan was prepared according to a method elaborated in the Institute of Biopolymers and Chemical Fibers, Polish patent application P 393758 (27/01/2011).

\subsubsection{Preparation of Microcrystalline Chitosan Powder}

The microcrystalline chitosan powder, was prepared by freeze-drying using the laboratory lyophilizing cabinet ALFA 1 - 4 made by Christ Co. The freeze drying proceeded in the temperature range of $-20^{\circ} \mathrm{C}$ to $10^{\circ} \mathrm{C}$ and vacuum 0.1 - 0.7 mbar. The drying time was 20 - 24 hours.

\subsubsection{Preparation of Composite Film}

The MCCh/hydroxyapatite composite film, was prepared in the T-50 homogenizer made by IKA-WERKE, Germany. The composite components were blended at 4000 r.p.m. of the agitator at $20^{\circ} \mathrm{C}-30^{\circ} \mathrm{C}$. Prepared mixtures were poured out on Teflon plates, and dried at room temperature to obtain samples in form of films.

\subsubsection{Preparation of MCCh/Hydroxyapatite Composite Sponges}

The sponges were prepared from a mixture composed of an aqueous suspension of MCCh, according to composites showed in Table 1 . The preparation was first carefully homogenized and next freeze-dried in a lab freeze dryer ALFA 1 - 4 made by Christ Co in the temperature range from $-25^{\circ} \mathrm{C}$ to $10^{\circ} \mathrm{C}$ and vacuum from 0.1 to 0.53 mbar during 20 to 24 hours depending upon size of the charge. Drying accomplished that way resulted in the preparation of sponges with a smooth surface without defects.

\subsubsection{Elaboration of the Quantitative and Qualitative Composite MCCh/HAp}

The main objective of this study was elaboration of qualitative and quantitative composition of MCCh/HAp composites.

The quantitative and qualitative preparations of the composites are presented in Table 1, the polymer content of the samples is related with dry polymer and the glycerol content added in the samples is related with polymer content and HAp content.

\subsubsection{SEM Study}

The particle size, morphology, structure and distribution, were observed using a scanning electron microscopy (SEM) - FEI Quanta 200, USA. The sizes of particles of hydroxyapatite were calculated using analysis Docu Soft Imaging System firm.

\subsubsection{Infrared Spectroscopy}

Infrared spectroscopy Fourier transform (FTIR) is a non-destructive technique that was used to identify the functional groups through their chemical bonds, which generate a spectrum of infrared bands characteristic of each connection type. The infrared analysis was performed on a range of 500 to $4000 \mathrm{~cm}^{-1}$, resolution $4.0 \mathrm{~cm}^{-1}$ with a Spectrum Genesis Series. Samples were prepared for analysis with $\mathrm{KBr}$, in form of tablets. To verify the presence of functional characteristic groups of the HAp and MCCh in the composite material.

\subsubsection{Mechanical Properties Study}

The mechanical properties of the composites in film and sponge forms were determined in the Accredited Laboratory of Metrology at IBWCh (certificate No. AB 388) by using dynamometer Instron (type 5544) according to the following standards (Polish Standard PN-EN-ISO 527-1. Polish Standard PN-EN-ISO 527-3, Polish Standard PN-ISO 4593).

\section{Results and Discussion}

\subsection{Characterization of Initial Chitosan}

Materials have shown the chemical characteristics of the initial chitosan and the MCCh, used in this research. 
Table 1. Characteristic of MCCh/HAp composites.

\begin{tabular}{ccccc}
\hline \multirow{2}{*}{ Symbol of sample } & \multicolumn{3}{c}{ Weight proportion of components } \\
\cline { 2 - 5 } & MCCh (suspension) & MCCh (powder) & HAp & 0 \\
Sample 1 & $1^{*}$ & 0 & 0 & 0.25 \\
Sample 2 & $1^{*}$ & 0 & 0.5 & 0 \\
Sample 3 & $1^{*}$ & 0 & 0.5 & 0.25 \\
Sample 4 & $1^{*}$ & 0 & 1 & 0.25 \\
Sample 5 & $1^{*}$ & 0 & 2 & 0.25 \\
Sample 6 & $1^{*}$ & 0 & 0.5 & 0.5 \\
Sample 7 & $1^{*}$ & 0 & 1 & 0.5 \\
Sample 8 & $1^{*}$ & 0 & 2 & 0.5 \\
Sample 9 & $1^{*}$ & 0 & 2 & 0.5 \\
Sample 10 & $1^{* *}$ & 0 & 2 & 0.5 \\
Sample 11 & $1^{*}$ & 1 & & \\
\hline
\end{tabular}

* Dry polymer content 2.0\%; ${ }^{* * *}$ Dry polymer content $2.95 \%$.

The results have shown a high reduction in the ash content in the MCCh and a high improvement in the water retention value, explained by the inner surface formation related with the amorphous part. Suggest good Hemostatic properties following the literature [11]-[13].

\subsection{FTIR Study}

The main peaks of energy vibration identified in the HAp (Figure 1(a)), have shown the characteristic functional groups of orthophosphate $\left(\mathrm{PO}_{4}^{-3}\right)$, hydroxyl $(\mathrm{OH})^{-}$, phosphate $\left(\mathrm{HPO}_{4}^{-2}\right)$ and probably pyrophosphate $\left(\mathrm{P}_{2} \mathrm{O}_{7}^{-2}\right)$, the latter two in trace amount, since their peaks are not significant and not observed in other positions of the spectrum, characteristics of these material. The presence of carbonate group, also in trace amount, is characteristic peak from commercial HAp is $\left(1465-1415 \mathrm{~cm}^{-1}\right.$ and $\left.876 \mathrm{~cm}^{-1}\right)$ [15] [16]. Those peaks suggest that in some commercial $\mathrm{HAp}$ the $\mathrm{CaO}$ and $\mathrm{Ca}(\mathrm{OH})_{2}$ are used to get an ideal stoichiometric relation between $\mathrm{Ca} / \mathrm{P}$ in the material. These features can prevent or decrease the regeneration of bone tissue in the presence of an implant. Thus, it is desirable that the material replacements for bones present some solubility to allow this regeneration, which can be achieved with a carbonated hydroxyapatite [17]-[20].

In the spectrum of the HAp sample, there have been shown the peaks at $839 \mathrm{~cm}^{-1}$ that correspond a deformation modes of phosphate groups (O-P-H) bonds, associated with energy level and with the rotational type of the bound O-H. In $3570 \mathrm{~cm}^{-1}$ and $3464 \mathrm{~cm}^{-1}$ is observed also the $\mathrm{OH}^{-}$group peak, referring to the way they stretch. The band observed at $962 \mathrm{~cm}^{-1}$ of low intensity, corresponding to non-degenerate symmetric stretching of P-O bonds of phosphate groups. The bands 1040 and $1093\left(\mathrm{~cm}^{-1}\right)$ represent the asymmetric stretch modes, respectively, the P-O bonds of phosphate groups [10] [19] [21].

There is presence of adsorbed water in the starting materials for the existence of peaks associated in the regions of 1590, $1630\left(\mathrm{~cm}^{-1}\right)$ and the peaks around $3400 \mathrm{~cm}^{-1}$ [5] [8] [16] [19]. The peaks of MCCh in Figure 1(b), confirm the presence of the functional groups $\mathrm{NH}_{2}\left(1506 \mathrm{~cm}^{-1}\right)$, Amide I $\left(1637 \mathrm{~cm}^{-1}\right)$, amide II $\left(1559 \mathrm{~cm}^{-1}\right)$ in the material and the main peaks of energy vibration $\left(1032,1086 \mathrm{~cm}^{-1}\right)$ identified the MCCh. Figure 1(c), shows the FTIR spectra of MCCh/HAp composite. The spectrum exhibits characteristic bands such as: a strong and broad peak between $1032 \mathrm{~cm}^{-1}$ and $1086 \mathrm{~cm}^{-1}$ and $1160 \mathrm{~cm}^{-1}$ that refer to the skeletal vibrations stretch of saccharide structure and a peak at $1559,1543 \mathrm{~cm}^{-1}$ attributed to the free primary amino group $\left(\mathrm{NH}_{2}\right)$ in MCCh [10] [11] [22] [23]. Main peaks of energy vibration identified in the HAp for characteristic functional groups of orthophosphate $\left(\mathrm{PO}_{4}^{-3}\right)$ at $1100 \mathrm{~cm}^{-1}$, hydroxyl $(\mathrm{OH})^{-}$at 3700 and $2600 \mathrm{~cm}^{-1}$, phosphate $\left(\mathrm{HPO}_{4}^{-2}\right)$ at $1000 \mathrm{~cm}^{-1}$. A broad band appears from 2600 and 3566 and $3700 \mathrm{~cm}^{-1}$ corresponding to the -OH stretching absorption band in the samples. The possible chemical interactions between the inorganic and organic constituents in the composite, probably take place by the chemical bonding between $\mathrm{Ca}^{2+}$, phosphate groups and the amino group of MCCh [10] [11] [21] [24] [25].

It is important to note that the spectrum does not present glycerol interference peaks in the areas of the two peaks of interest, that suggest no chemical reaction between MCCh/HAp and glycerol. All bands features are 


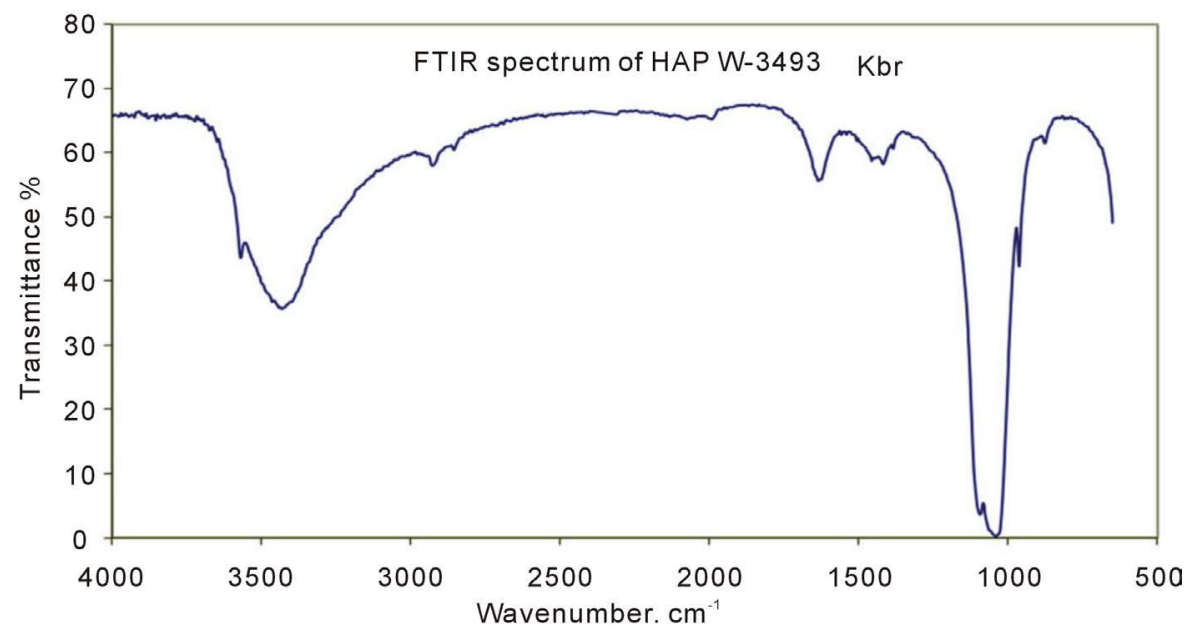

(a)

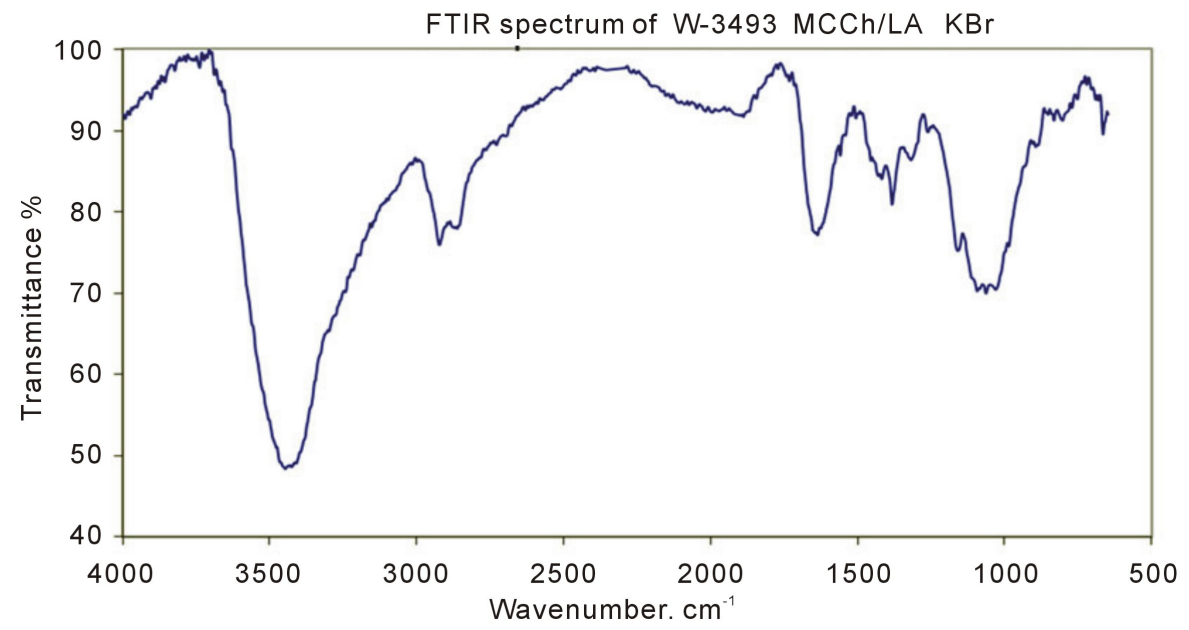

(b)

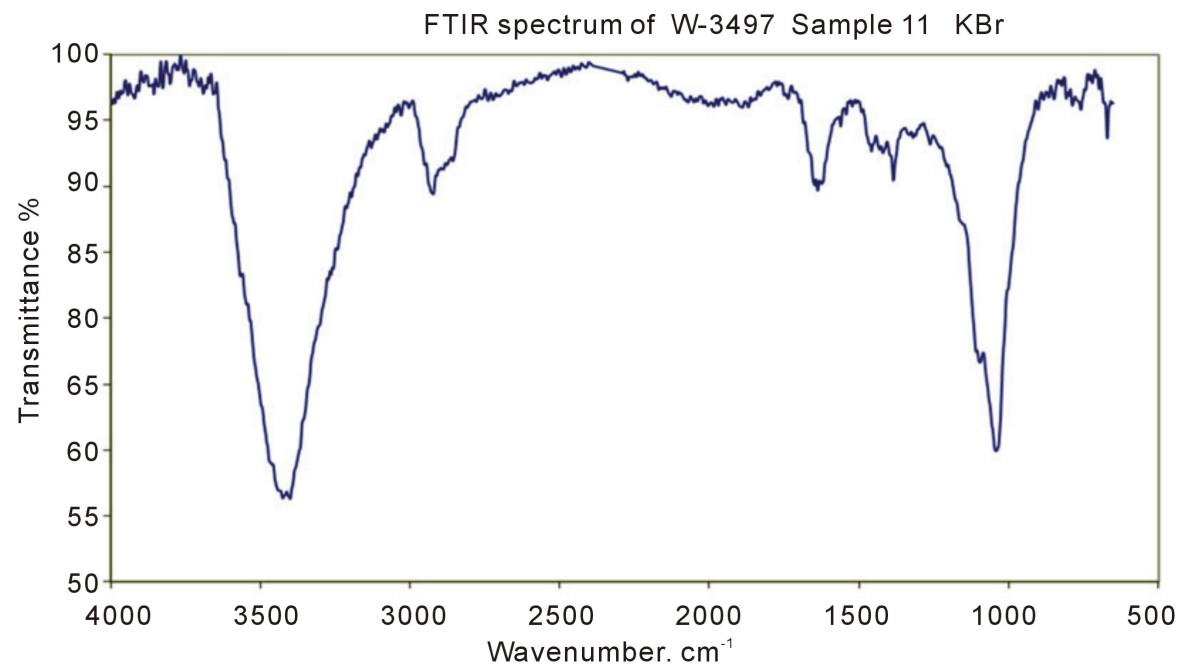

(b)

Figure 1. (a) FTIR spectrum of the commercial HAp, (b) FTIR spectrum of the MCCh, (c) FTIR spectrum of the composite sample 11. 
very similar to those described by Brugnerotto et al. [16] and are present in all samples investigated, showing that all have basically the same functional groups.

\subsection{Analysis of the Particles Size of the Hydroxyapatite}

The aim of this study was to determine the particle size and morphology of the commercial hydroxyapatite powder shown in Figure 2(a) and Figure (b). Before analyzing the HAp was dried with vacuum at $105^{\circ} \mathrm{C}$ for 24 $\mathrm{h}$ to remove moisture and separated for morphology study of the particles by SEM. In Figure 2(b), can also be seen a size of HAp grain in fair agreement with particles size reported in literature [11] [15] [22] [23]. Notice in the Figure 2(a), a cluster formations that shown a water absorption characteristic of the calcium phosphates powders.

Grain size fits mainly in the range $1.0-10.0 \mu \mathrm{m}$, average particle size of HAp is $3.24 \pm 0.81 \mu \mathrm{m}$, also according with the literature [15] [19] [24] [25].

\subsection{SEM Study of the Films}

The objective of the investigation was to estimate the suitability of those preparations for dressings in films form, stability of the suspension and HAp distribution in the polymer matrix. The SEM analysis showed a HAp great ability to agglomeration and cluster formation, the small particles tend to agglomerate due to the increased intensity of the attractive forces on the repulsive, because the charge distribution on the surfaces and the water adsorption [15] [19] [25]. Samples 10 and 11 were chosen for further studies because shown the best structure and the highest content of calcium phosphates of the set of samples according with Table 1 . The sample 1 (just $\mathrm{MCCh}$ ) is a reference.

The increase of the plasticizer content in MCCh/HAp preparations to 0.5 wt. parts is beneficial for a more uniform distribution of HAp particles in the polymer matrix.

Increasing the polymer content in MCCh suspension to $2.95 \%$ does not inhibit the sedimentation process of the HAp particles in the polymer matrix (Figure 3). Additions of MCCh in form of powder to the suspension inhibits the sedimentation process and give more stability for the suspension, the HAp particles in the film had more homogeneous distribution in the whole volume of the polymer matrix (Figure 4).

Samples 10 and 11 were chosen for further studies because shown the best structure and the highest content of calcium phosphates of the set of samples according with Table 1. Sample 1 (just MCCh) is a reference. Figure 5 shows the surface and cross section picture of the clear MCCh (no calcium Phosphates) in film form.

\subsection{SEM Study of the Sponges}

The objective of the investigation was to estimate the suitability of those preparations for sponge form, study of the structure and the HAp distribution in the polymer matrix. The SEM analysis showed a HAp also a great ability to agglomeration and cluster formation, showing the same behavior of the films preparation. Was chosen the samples 10 and 11 because they show the best structure and the highest content of calcium phosphates of the set of samples and the sample 1 is a reference.

The preparations with HAp/MCCh formed a well-shaped 3-dimensional interconnected structure which can be used in future as a base for scaffolds production. The HAp particle aggregates well in the polymer matrix of MCCh with homogenous distribution [19]. Increase of the plasticizer content in $\mathrm{MCCh} / \mathrm{HAp}$ preparations to $0.5 \mathrm{wt}$. parts is beneficial for a more uniform distribution of HAp particles in the polymer matrix. To increase the polymer content of MCCh suspension to 2.95\% (Figure 6) gave more homogenous structure reducing the size of the porous increasing the porosity and a uniform distribution of the HAp in the polymer matrix. Addition of MCCh in form of powder to the suspension improves and profitably affects the uniformity of their distribution in the whole volume of the polymer matrix (Figure 7), more stability of the suspension giving also a good homogenous structure of the porous and good HAp distribution. Sample 1 showed in Table 1 (just MCCh) is a reference. Figure 8 shows the surface and cross section picture of the clear MCCh (no calcium Phosphates) in sponge form.

\subsection{The Physical-Mechanical Tests of Composite MCCh/HAp Film}

Table 2 shows the physical-mechanical tests of the selected composite MCCh/HAp films, according to Table 1.

Analyzing the results it can be noted that with the addition of MCCh in form of powder (sample 11) in the suspension increased the tensile strength comparing with other samples and increase max force comparing with 


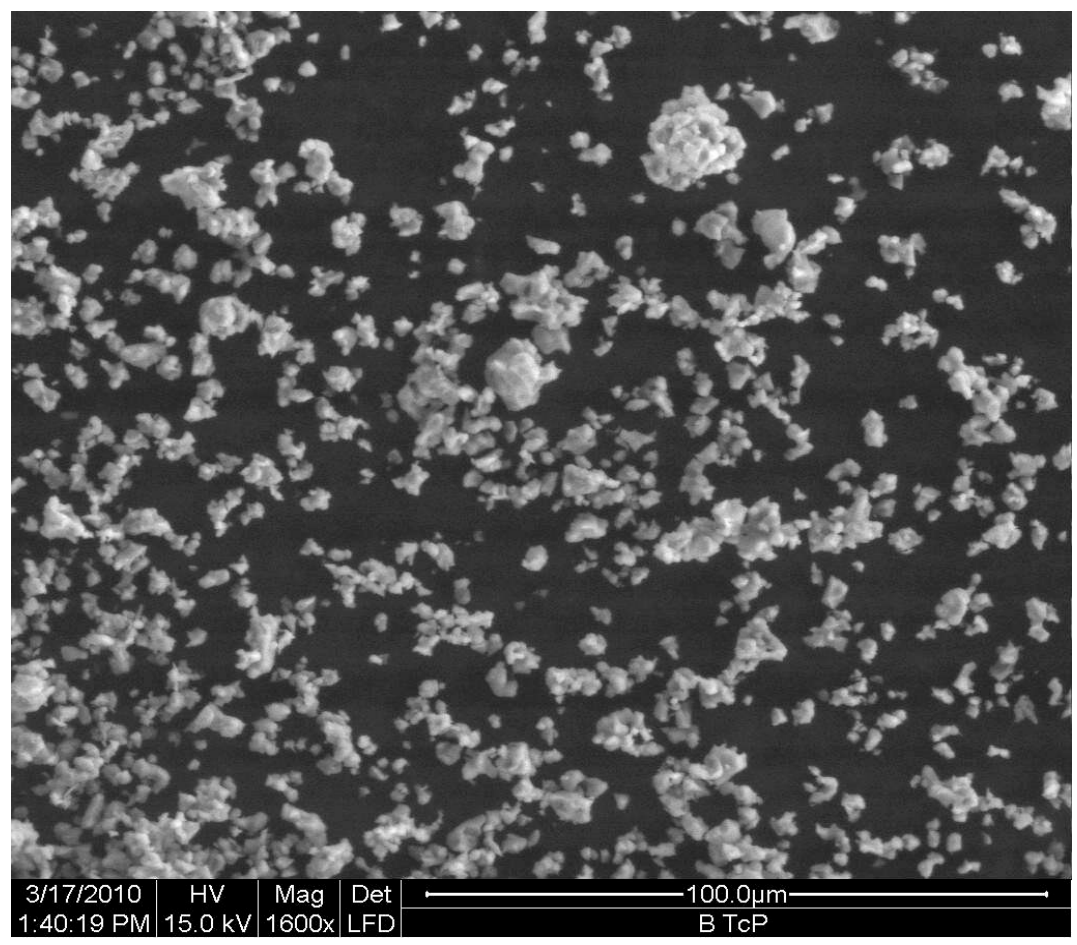

(a)

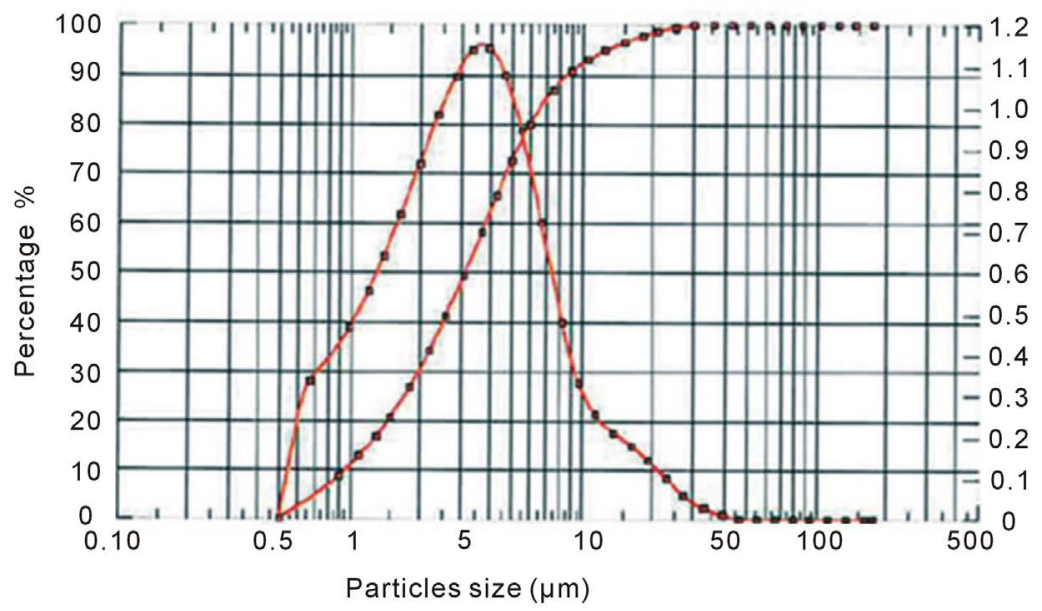

(b)

Figure 2. (a) SEM micrograph of HAp grain morphology, (b) Grain size distribution of HAp.

the sample 10, that suggests a homogeneous distribution the HAp in the polymer matrix and a stabilization of the dispersion and also related with the glycerol as a plastisizer.

The sample 10, which increases the polymer content showed a significant decrease in the mechanical properties, which suggests a low interaction between MCCh with HAp and showing, the increase of the inorganic part causes the decrease of the mechanical properties.

\subsection{The Physical-Mechanical Tests of Composite MCCh/HAp Sponges}

The mechanical properties of MCCh scaffolds are mainly dependent on the quantity and the sizes of pores [19] [20] [24]. Table 3 shows the physical-mechanical tests of the selected composite MCCh/HAp sponges, according to Table 1. 

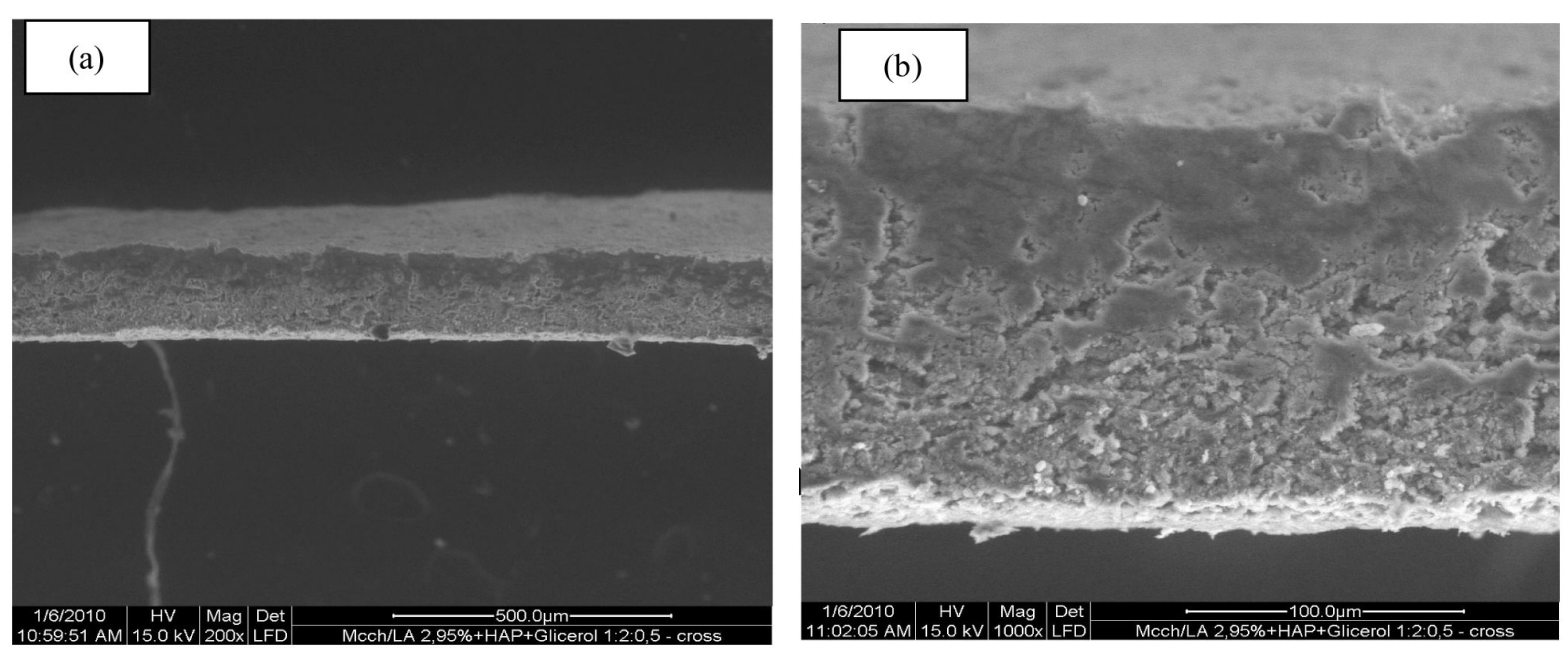

Figure 3. SEM photos cross-section, (a) 200×, (b) 1000× of Sample 10.
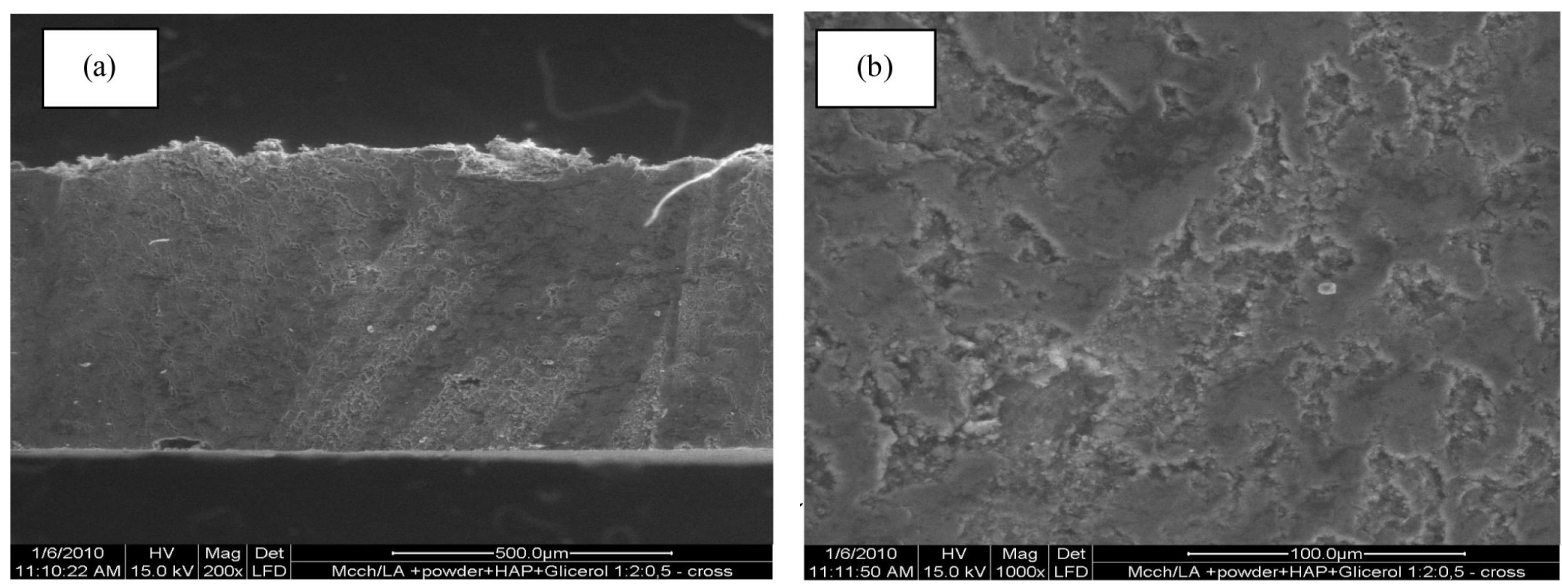

Figure 4. SEM photos cross-section, (a) 200×, (b) 1000× of Sample 11.
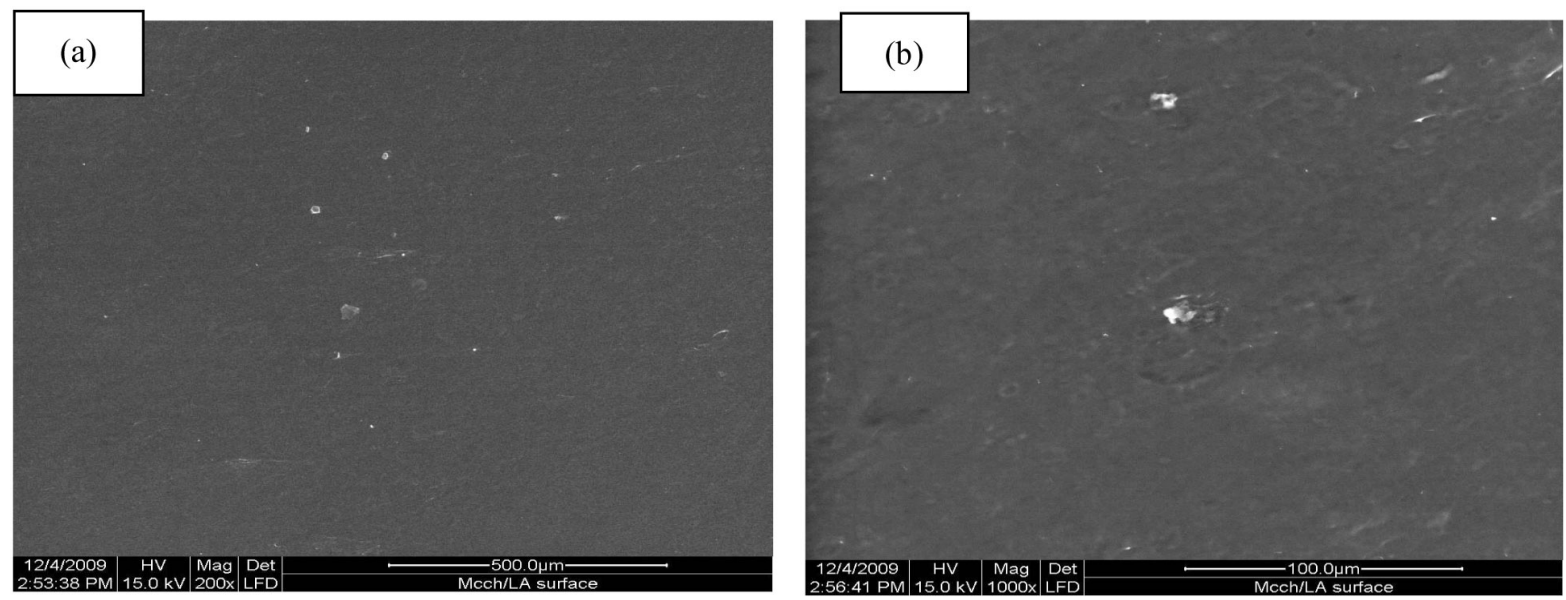

Figure 5. SEM photos surface, (a), cross-section 200×, (b) cross-section 1000× of sample.

Scaffolds for bone tissue engineering must have a highly porous and interconnected pore structure to ensure a biological environment conducive to cell attachment and proliferation as well as tissue growth, they also have to provide the passage of nutrient flow [24]. The significant decrease in tensile strength (MPa) and max force (N) 

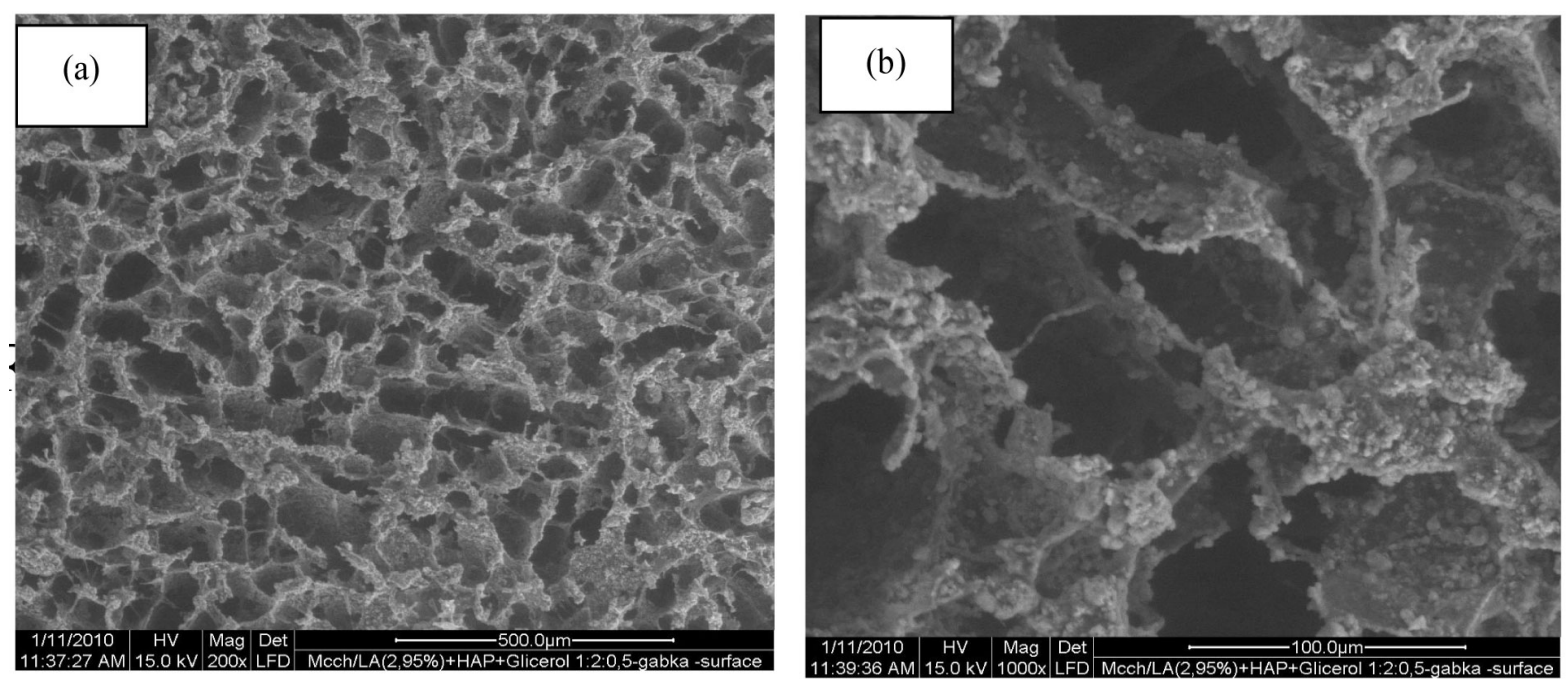

Figure 6. SEM photos surface, (a) 200×, (b) 1000× cross-section of Sample 10.
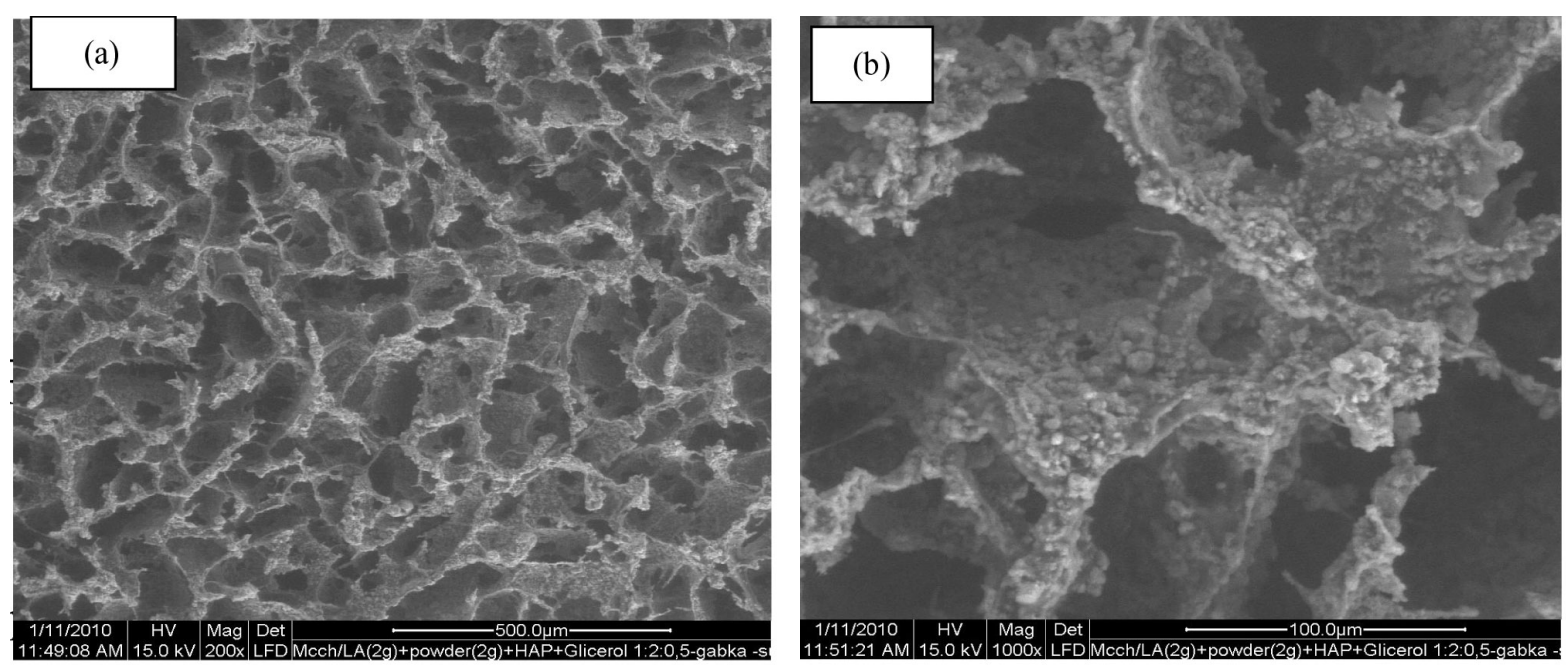

Figure 7. SEM photos surface, (a) 200×, (b) 1000× cross-section of Sample 11.
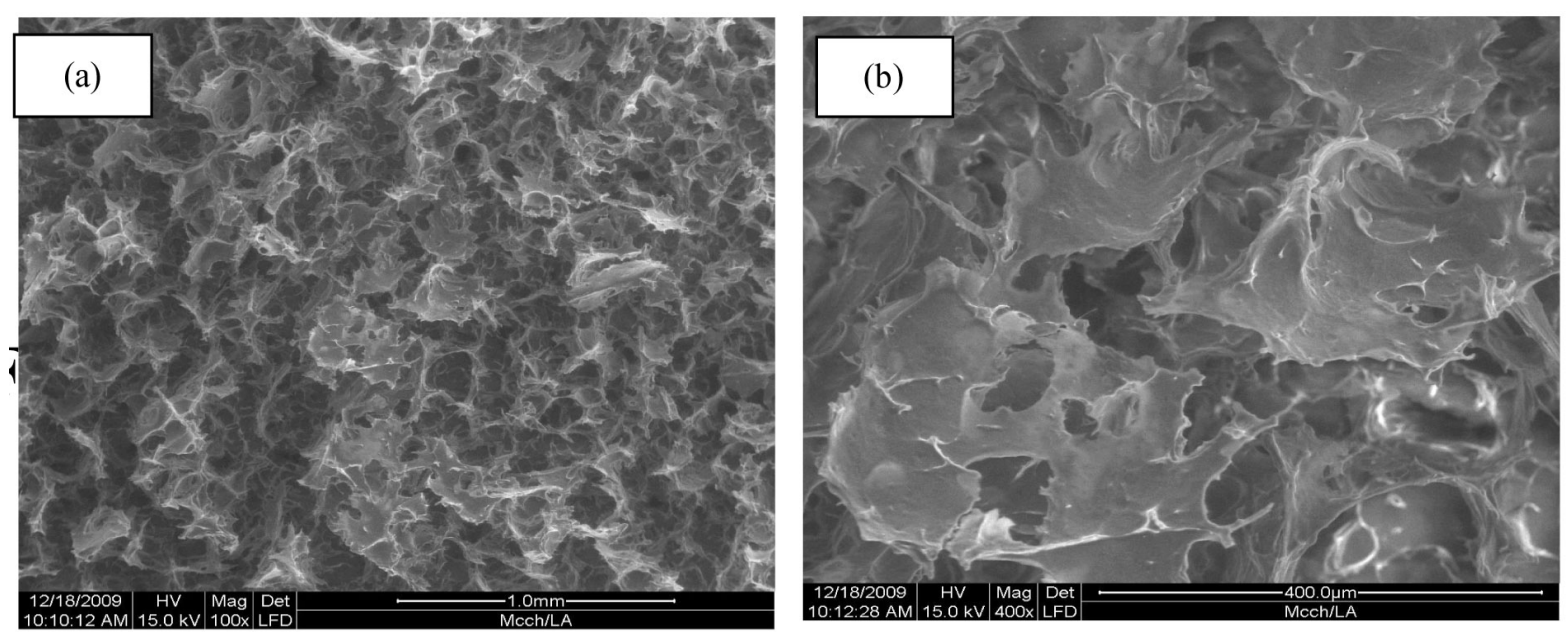

Figure 8. SEM photos surface, (a) 200×, (b) $1000 \times$ cross-section of Sample 1. 
Table 2. physical-mechanical parameters of the selected composites MCCh/HAp.

\begin{tabular}{cccc}
\hline Parameters & \multicolumn{3}{c}{ Samples } \\
\hline & 1 & 10 & 11 \\
\hline Max force (N) & 11.4 & 10.8 & 38.2 \\
C.V. (\%) & 7.18 & 29.6 & 12.0 \\
Tensile strength (MPa) & 11.4 & 1.59 & 5.59 \\
C.V. (\%) & 9.44 & 15.2 & 14.1 \\
Elongation at break (\%) & 6.3 & 3.63 & 2.18 \\
C.V. (\%) & 13.1 & 26.8 & 14.1 \\
\hline
\end{tabular}

Table 3. Physical-mechanical parameters of composite MCCh/Hap.

\begin{tabular}{|c|c|c|c|}
\hline \multirow[t]{2}{*}{ Paramet } & \multicolumn{3}{|c|}{ Samples } \\
\hline & 1 & 10 & 11 \\
\hline Max force $(\mathrm{N})$ & 6.12 & 0.21 & 0.24 \\
\hline C.V. $(\%)$ & 20.4 & 28.0 & 16.1 \\
\hline Tensile strength (MPa) & 0.172 & 0.006 & 0.007 \\
\hline C.V. $(\%)$ & 20.4 & 28.0 & 16.1 \\
\hline Elongation at break (\%) & 1.53 & 3.75 & 5.67 \\
\hline C.V. (\%) & 15.2 & 22.2 & 16.1 \\
\hline
\end{tabular}

for the MCCh/HAp composites sponges can be attributed to a great number of open pores in the sponge form, the increase the elongation at break, also suggest a glycerol influence reducing the intermolecular interaction improving the polymer chains mobility. The same behaviour can also notice, when HAp content increase the mechanical properties decrease.

\section{Conclusions}

1) Increasing the plasticizer content in MCCh/Hap preparations shown more uniform distribution of Hap particles in the polymer matrix in the films and sponges preparation and addition of MCCh in form of powder to the suspension inhibits the process of sedimentation of the Hap particles in the films preparation.

2) Increasing the Hap content in the composites decreases the mechanical properties, indicating a low chemical interaction between MCCh and Hap.

3) The FTIR study confirms the presence of functional characteristic groups of the HAp: P-O, O-H, P-O-H, $\mathrm{H}-\mathrm{O}-\mathrm{H}, \mathrm{C}-\mathrm{O}$, and the MCCh $\left(\mathrm{NH}_{2}\right.$, amide I, II group), in the composites with no side reactions.

4) The sponge preparations with HAp/MCCh formed a well-shaped 3-dimentional structure which can be used in future as a base for scaffolds production. The HAp aggregates well in the polymer matrix of MCCh showing a homogeneous structure and distribution in the polymer matrix.

\section{Acknowledgements}

The research and the work presented herewith are carried out with its financially sponsored by the European Community’s Seventh Framework Program ("Marie Curie Initial Training Network), FP7/2007-2013.

Thuringian Institute of Textile and Plastics Research, Rudolstadt, Germany.

\section{References}

[1] Barbosa, M.A., Granja, P.L., Barrias, C.C. and Amaral, I.F. (2005) Polysaccharides as Scaffolds for Bone Regeneration. ITBM-RBM, 26, 212-217. http://dx.doi.org/10.1016/j.rbmret.2005.04.006

[2] Muzzarelli, R.A.A. (1995) Chitin and the Human Body. 1st International Conference of the European Chitin Society. Advances in Chitin Science, Brest, 448-461.

[3] Puttipipatkhachorn, S., Nunthanid, J., Yamamoto, K. and Peck, G.E. (2001) Drug Physical State and Drug-Polymer Interaction on Drug Release from Chitosan Matrix Films. Journal of Controlled Release, 75, 143-153. http://dx.doi.org/10.1016/S0168-3659(01)00389-3

[4] Henryk, P. and Wojciech, F. (2004) Factors Modifying a Biological Activity of Chitin Derivatives. Progress on Che- 
mistry and Application of Chitin and Its Derivatives, PTChit, X, 7-12.

[5] Jue-Yeon, L., Sung-Heon, N., Su-Yeon, I., Yoon-Jeong, P., Yong-Moo, L., Yang-Jo, S., Chong-Pyoung, C. and SeungJin, L. (2002) Enhanced Bone Formation by Controlled Growth Factor Delivery from Chitosan-Based Biomaterials. Journal of Controlled Release, 78, 187-197. http://dx.doi.org/10.1016/S0168-3659(01)00498-9

[6] Viala, S., Frenche, M. and Lacout, J.L. (1998) Preparation of a New Organic-Mineral Composite-Chitosan and Hydroxyapatite. Annales de Chimie Science des Matériaux, 23, 69-72. http://dx.doi.org/10.1016/S0151-9107(98)80025-1

[7] Fathi, M.H., Hanifi, A. and Mortazavi, V. (2008) Preparation and Bioactivity Evaluation of Bone-Like Hydroxyapatite Nanopowder. Journal of Materials Processing Technology, 202, 536-542.

[8] Dorozhkin, S.V. (2009) Calcium Orthophosphates in Nature, Biology and Medicine Review. Materials, 2, 399-498. http://dx.doi.org/10.3390/ma2020399

[9] Gauthier, O., Goyenvalle, E., Bouler, J.M., Guicheus, J., Pilet, P., Weiss, P. and Daculsi, G. (2001) Macroporous Biphasic Calcium Phosphate Ceramics versus Injectable Bone Substitute: A Comparative Study 3 and 8 Weeks after Implantation in Rabbit Bone. The Journal of Materials Science: Materials in Medicine, 12, 385-390. http://dx.doi.org/10.1023/A:1011284517429

[10] Pighinelli, L., Kucharska, M., Brzoza-Malczewska, K. and Gruchała, B. (2011) Complex Microcrystalline Chitosan/TriCalcium Orthophosphate and Process for Preparing Same. Poland Patent Application P 393758.

[11] Struszczyk, H.M. (2003) The Effect of the Preparation Method on the Physicochemical Properties of Microcrystalline Chitosan (MCCh). Progress on Chemistry and Application of Chitin and Its Derivatives, PTChit, IX, 179-186.

[12] Skoog, H.N. (2006) Principios de Analise Instrumental. $5^{\text {a }}$ Ediçao, Bookman, 342-384.

[13] Struszczyk, H.M. (2006) Global Requirements for Medical Applications of Chitin and Its Derivatives. Progress on Chemistry and Application of Chitin and Its Derivatives, PTChit, XI, 95-102.

[14] Barbosa, M.A., Granja, P.L., Barrias, C.C. and Amaral, I.F. (2005) Polysaccharides as Scaffolds for Bone Regeneration. ITBM-RBM, 26, 212-217. http://dx.doi.org/10.1016/j.rbmret.2005.04.006

[15] Wawro, D. and Pighinelli, L. (2011) Chitosan Fibers Modified with HAp/ $\beta$-TCP Nanoparticles. International Journal of Molecular Science, 12, 7286-7300. http://dx.doi.org/10.3390/ijms12117286

[16] Brugnerotto, J., Lizardi, J., Goycoolea, F.M., ArguÈelles-Monal, W., DesbrieÁres, J. and Rinaudo, M. (2001) An Infrared Investigation in Relation with Chitin and Chitosan Characterization. Polymer, 42, 3569-3580. http://dx.doi.org/10.1016/S0032-3861(00)00713-8

[17] Ratajska, M., Haberko, K., Cienchanska, D., Niekraszewicz, A. and Kucharska M. (2008) Hydroxiapatite-Chitosan Biocomposites. Progress on Chemistry and Application of Chitin and Its Derivatives, PTChit, XIII, 89-94.

[18] Lei, L. and You-Lo, H. (2006) Chitosan Bicomponent Nanofibers and Nanoporous Fibers. Carbohydrate Research, 341, 374-381. http://dx.doi.org/10.1016/j.carres.2005.11.028

[19] Wawro, D., Pighinelli, L. and Stęplewski, W. (2010) Methods of Manufacture Composite Chitosan Fibers. Poland Patent Application P 393022, 23.

[20] Hockin, H.K. Xu, C. and Simon Jr., G. (2005) Fast Setting Calcium Phosphate-Chitosan Scaffold:Mechanical Properties and Biocompatibility. Biomaterials, 26, 1337-1348. http://dx.doi.org/10.1016/j.biomaterials.2004.04.043

[21] Ratajska, M., Haberko, K., Cienchanska, D., Niekraszewicz, A. and Kucharska, M. (2008) Hydroxiapatite-Chitosan Biocomposites. Progress on Chemistry and Application of Chitin and Its Derivatives, PTChit, XIII, 89-94.

[22] Maachou, H., Bal, K.E., Bal, Y., Chagnes, A., Cote, G. and Alliouche, D. (2008) Characterization and in Vitro Bioactivity of Chitosan/Hydroxyapatite Composite Membrane Prepared by Freeze-Gelation Method, Trends Biomater. Artif. Organs, 22, 1.

[23] Sundararajan, V.M. and Matthew, H.W.T. (1999) Porous Chitosan Scaffolds for Tissue Engineering. Biomaterials, 20, 1133-1142. http://dx.doi.org/10.1016/S0142-9612(99)00011-3

[24] Jae-Young, R., Liisa, K.-S. and Peter, Z. (1998) Mechanical Properties and the Hierarchical Structure of Bone. Medical Engineering \& Physics, 20, 92-102. http://dx.doi.org/10.1016/S1350-4533(98)00007-1

[25] Luciano, P. and Magdalena, K. (2013) Properties of Microcrystalline Chitosan-Calcium Phosphate Complex Composite. Journal of Biomaterials and Nanobiotechnology, 4, 20-29. http://dx.doi.org/10.4236/jbnb.2013.44A003 